\title{
Clinical correlation between hla-b27 and inflammatory marker in case of ankylosing spondylitis (AS)
}

\begin{abstract}
Aims: The aim of the study is to establish the correlation among $\mathrm{CRP}(\mathrm{C}$ reactive protein), ESR (erythrocyte sedimentation rate) and Rheumatoid factor in case of HLA-B27 positive and negative patients in comparison to healthy control.

Materials and Methods: Eighty patients were selected for study in which 40 with AS 40 controls. The clinical and laboratory data including erythrocyte sedimentation rate (ESR), C-reactive protein (CRP) and HLA-B27 of patients were recorded.

Results: The mean age of 40 patients was $31.6 \pm 9.77$ years. HLA-B27 was positive in 48 patients $(60 \%)$ and it was found that disease activity was significantly associated with serum concentrations of CRP and ESR. In contrast, in the HLA B27- patients concentrations of ESR were significantly associated with disease activity, but not the concentrations of CRP.

Conclusion: These results indicates that the known difference between HLA B27 positive and HLA B27 negative AS and suggest that the different pathogenic mechanisms involve in the two forms of AS, and the geographic regions and also the age at which the illness begins is one of the important predictors for the functional and clinical status in the disease course in Indian population.
\end{abstract}

Volume 4 Issue 2 - 2016

\author{
SS Haque, ${ }^{2}$ Santosh Kumar,' MK Sinha, ${ }^{3}$ Rawi \\ Agrawal, ${ }^{3}$ Anju singh, ${ }^{4}$ Uday Kumar ${ }^{5}$ \\ IIndira Gandhi Institute of Medical Sciences, India \\ ${ }^{2}$ Department of Orthopedics, Department of Biochemistry, \\ Indira Gandhi Institute of Medical Sciences, India \\ ${ }^{3}$ Department of Biochemistry, Patna Medical College and \\ Hospital, India \\ ${ }^{4}$ Department of Pathology, Indira Gandhi Institute of Medical \\ Sciences, India \\ ${ }^{5}$ Department of Gastroenterology, Indira Gandhi Institute of \\ Medical Sciences, India
}

\begin{abstract}
Correspondence: SS Haque, Department of Orthopedics, Department of Biochemistry, Indira Gandhi Institute of Medical Sciences, India, Email sshaq2002@yahoo.co.in
\end{abstract}

Received: September 21,2016 | Published: October 20, 2016

Keywords: ankylosing spondylitis, human leukocyte antigen- b27, c-reactive protein

Abbreviations: AS, ankylosing spondylitis; CRP, C-reactive protein; ESR, erythrocyte sedimentation rate; HLA-B27, human leukocyte antigen

\section{Introduction}

Ankylosing spondylitis (AS) shows a strong correlation with human leukocyte antigen (HLA-B27), and number of evidence suggests that the B27 gene may have a pathogenic role in the development of AS and HLA-B27 has a tendency for familial association. ${ }^{1-3}$ The association of HLA-B27 with Ankylosing spondylitis was first described in 1973, ${ }^{4}$ and is among the strongest described for a HLA locus. The frequency of HLA-B27 with AS among Indian population varies from 40 to $94 \%$ as compared to $1.4-8 \%$ of the general population. ${ }^{5}$ HLA-B27 is a unique HLA class I molecule, not only because of its high association with AS but also has characteristically different amino acid composition from other class I molecules. There are two important characteristic structures which are different from others: the presence of B pocket and the free thiol group of Cys67. ${ }^{6,7}$ We performed this study to find out pathophysiological differences between B27+ and B27-patients with AS and relate these differences to the serum concentrations of CRP, ESR (erythrocyte sedimentation rate) and RF (Rheumatoid factor) to determine whether the B27 status and presence or absence of disease activity could predict the concentrations of CRP and ESR. ESR and CRP are two currently used biomarkers for the evaluation of inflammatory activity of the disease. However, these biomarkers do not have the most ideal specificity, sensitivity, and reproducibility characteristics.

Both ESR and CRP have been shown to be useful indicators of disease activity in other rheumatic diseases such as rheumatoid arthritis. ${ }^{8}$ High levels of CRP are found during acute infection, tissue injury, or inflammatory disease. The molecule is capable of activating the complement cascade and initiates both the opsonic and lytic potentials of this system. ${ }^{9-11}$ These characteristics suggest that CRP may play an important role in the mediation of inflammatory responses.

\section{Materials and methods}

\section{Study subjects}

We included a total of 80 patients in 40 AS patients (28 male and 12 female) and 40 control subjects ( 30 male and 10 female). AS diagnoses were made according to Assessment in AS International Working Group criteria. Control subjects were selected randomly from healthy subjects. AS patients were selected randomly from among follow-up patients. Venous blood samples were obtained from fasting patients. HLA-B27- carriage was identified by flow cytometry. Disease activity was assessed by laboratory parameters including ESR and CRP. C-reactive protein (CRP) and erythrocyte sedimentation rate (ESR) were measured and evaluated as inflammatory markers of AS. Serum CRP levels was measured by the immunonephelometric method (Siemens, Munich, Germany) according to the manufacturer's instructions and results were expressed as $\mathrm{mg} / \mathrm{L}$. ESR was measured by capillary photometry and results were expressed as $\mathrm{mm} / \mathrm{hr}$ The study was approved by the local ethics committee. All subject demographic data (history of disease, smoking status, disease duration, medications received) were recorded. Physical examination of the study participants was done by a specialist in physical rehabilitation and medicine.

\section{Results}

Out of 80 cases, only 48 patients $(60 \%)$ were positive for HLA-B27. Four of the female patients were positive for HLA-B27, whereas 44 male out of 80 patients (55\%) were positive for HLA-B27. Correlation of joint involvement with HLA-B27 antigen positivity 
revealed that in HLA-B27-positive. Table 1 summarizes clinical features of the patients. Clinical evaluation of the patients showed elevated serum $\mathrm{C}$-reactive protein, erythrocyte sedimentation rate and Rheumatoid factor. The value is significant when compared with control $(* * * \mathrm{p}<0.001)$.

Table I ESR, CRP and RF in HLA-B27-positive B27-negative and Control patients

\begin{tabular}{llll}
\hline Parameters & $\begin{array}{l}\text { Mean } \pm \text { SD B27- } \\
\text { positive }\end{array}$ & $\begin{array}{l}\text { Mean } \pm \text { SD B27- } \\
\text { negative }\end{array}$ & $\begin{array}{l}\text { Mean } \pm \text { SD } \\
\text { Control }\end{array}$ \\
\hline Age & $32.2 \pm 12.76$ & $29.5 \pm 9.62$ & $31.6 \pm 9.77^{* * *}$ \\
$\begin{array}{l}\text { ESR }(\mathrm{mm} \text { in the } \\
\text { Ist hr) }\end{array}$ & $32.65 \pm 19.39$ & $25.72 \pm 14.24$ & $14.22 \pm 8.45^{* * *}$ \\
$\mathrm{CRP}(\mathrm{mg} / \mathrm{L})$ & $\mathrm{II} .5 \pm 10.9$ & $5.95 \pm 5.36$ & $3.31 \pm 2.12^{* * *}$ \\
$\mathrm{RF}(\mathrm{IU} / \mathrm{ml})$ & $5.1 \pm 2.1$ & $4.5 \pm 3.2$ & $3.1 \pm 1.9 * * *$ \\
\hline
\end{tabular}

\section{Discussion}

HLA-B27 with Ankylosing spondylitis has strong correlation known for a long time. But it is thought that in addition to B27, other HLA-B and DR alleles may increase susceptibility to the development of AS. ${ }^{12}$ In our study, B27 positivity was significantly higher in patients with AS (60\%) than in healthy controls. B27 has 75 alleles with regard to nucleotide sequence diversity compared with 62 known subtypes at the protein level. ${ }^{13}$ The gender and HLA-B27 seem to be effective on clinical status while having both peripheral and axial articular involvements may probably be efficient on functional status in Indian patients with AS. These findings may influence the timing of diagnosis and choice of the treatment when clinicians first evaluate the patient. In our study, we compare the HLA B27 positive patients to negative ones since it is widely accepted that B27-positive patients are likely to have more active disease and a worse disease course.

\section{Conclusion}

The most important point that we recognized was that gender distribution, HLA-B27 positivity or the factors which may affect clinical status and functional impairment, in patients with AS, varied between geographic regions and also the age at which the illness begins is one of the predictors for the functional and clinical status in the disease course in Indian population.

\section{Acknowledgments}

None.

\section{Conflicts of interest}

None.

\section{Funding}

None.

\section{References}

1. Goldin R H, Bluestone R. Tissue typing in rheumatic disease. Clin Rhewn Dis. 1976;2:231-252.

2. Khan MA. Ankylosing spondylitis and heterogeneity of HLA-B27. Semin Arthritis Rheum. 1988; 18(2):134-141.

3. Woodrow J C. Genetic aspects of spondyloarthropathies. Clin Rheum Dis. 1985;11(1):1-24.

4. Brewerton DA, Hart FD, Nicholls A, et al. Ankylosing spondylitis and HL-A27. Lancet. 1973; 1(7809):904-907.

5. Devraj JP, Anjali R, Kanjaksha G. Application of a simple in-house PCR-SSP technique for HLA-B $\square 27$ typing in Spondyloarthropathies (SpA) patients. Arthritis. 2013;2013(2013):4

6. Madden DR. The three-dimensional structure of peptide-MHC complexes. Ann Rev Immunol. 1955;13:587-622.

7. Powis SJ, Santos SG, Antoniou AN. Biochemical features of HLA-B27 and antigen processing. Adv Exp Med Biol. 2009;649:210-216.

8. Amos RS, Constable TJ, Crockson RA, et al. Rheumatoid arthritis: relation of serum $\mathrm{C}$-reactive protein and erythrocyte sedimentation rates to radiographic changes. $\mathrm{Br}$ Med J . 1977;1(6055): 195-197.

9. Siegel J, Osmand AP, Wilson MF, et al. Interactions of C-reactive protein with the complement system. It. C-reactive protein mediated consumption of complement by poly-L-lysine polymers and other polycations. J Exp Med. 1975;142(3):709-721.

10. Osmand AP, Mortensen RF, Siegel J, et al. Interactions of C-reactive protein with the complement system. III. Complement-dependent passive hemolysis initiated by CRP. J Exp Med. 1975;142(5):1065-1077.

11. Mortensen RF, Osmand AP, Lint TF, et al. Interaction of C-reactive protein with lymphocytes and monocytes, complement dependent adherence and phagocytosis. J Immunol. 1976;117(3):774-781.

12. Robinson WP, van der Linden SM, Khan MA. HLABw60 increases susceptibility to ankylosing spondylitis in HLAB27+ patients. Arthritis and Rheumatism. 1989;32(9):1135-1141.

13. Reveille JD. Major histocompatibility genes and ankylosing spondylitis. Best Pract Res Clin Rheumatol. 2006;20(3):601-609. 